\title{
Wandering spleen caused by subcapsular haemorrhage
}

\author{
Christine M. Kariya, ${ }^{1,2}$ Daniel H. Fowler, ${ }^{3}$ Pamela Stratton ${ }^{4}$
}

${ }^{1}$ Department of Thoracic and GI Oncology, Center for Cancer Research, Bethesda, Maryland, USA

${ }^{2}$ General Surgery Residency, University of Maryland Medical Center, Baltimore, Maryland, USA

${ }^{3}$ Experimental Transplantation and Immunology Branch, National Cancer Institute, Bethesda, Maryland, USA ${ }^{4}$ Intramural Research Program, National Institutes of Health, Bethesda, Maryland, USA

\section{Correspondence to} Dr Christine M. Kariya, christine.kariya@nih.gov

Accepted 30 June 2018

\section{DESCRIPTION}

A 51-year-old woman 8 years post- human leukocyte antigen (HLA)-matched allogeneic haematopoietic cell transplant presented to her gynaecologist with abdominal pain and a new, large abdominopelvic mass that had gradually grown over a few weeks. She reported severe vomiting followed by days of debilitating abdominal pain during a self-limited gastroenteritis 4 weeks earlier. Her medical history was notable for follicular lymphoma with associated splenomegaly. While she achieved complete remission after haematopoietic cell transplant, she continued to have thrombocytopaenia. She had no history of abdominal surgery and had one vaginal birth. At presentation, she complained of mild abdominal pain and fullness in her lower abdomen and denied other systemic or gastrointestinal symptoms. Her physical examination was notable only for a firm, non-tender abdominopelvic mass spanning most of her lower abdomen. Her labs were significant for thrombocytopaenia $(132 \mathrm{k} / \mathrm{uL})$ and mildly low white blood cell count (WBC $2.79 \mathrm{~K} / \mathrm{uL}$ ) and a normal haemoglobin and haematocrit (12.3 g/dL/36.9\%). A CT scan with intravenous contrast was performed and compared with prior scans. Imaging showed the spleen and an accompanying large subcapsular haematoma forming the large pelvic mass. The subcapsular haematoma disrupted the spleen's normal ligamentous attachments and had pulled it from its normal location (figure 1) into the pelvis by gravity (figures 2 and 3 ). During her uncomplicated open splenectomy, it was revealed that all normal attachments to the spleen were absent except for the vascular pedicle at the splenic hilum. She recovered well and by postoperative week 4, her blood counts normalised (WBC $5.47 \mathrm{~K} / \mathrm{uL}$, haemoglobin $12.7 \mathrm{~g} / \mathrm{dL}$, haematocrit

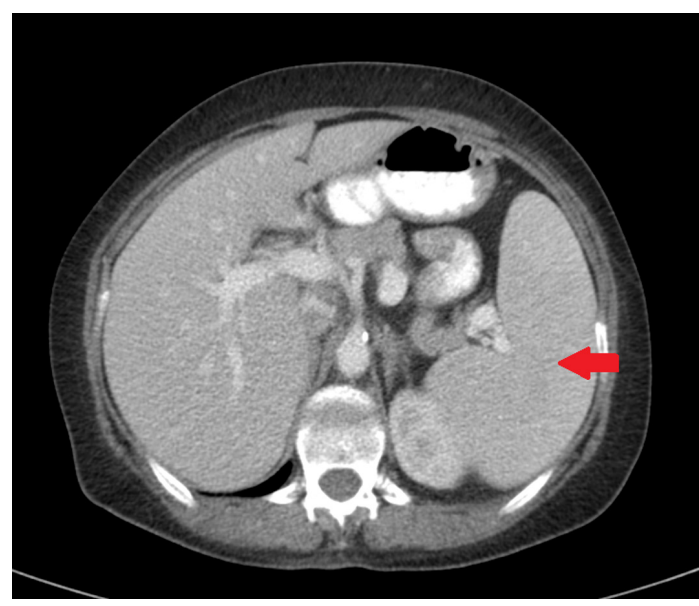

Figure 1 Abdominal axial CT scan from 7 years prior demonstrating the spleen (arrow) in its normal anatomic position in the left upper quadrant.

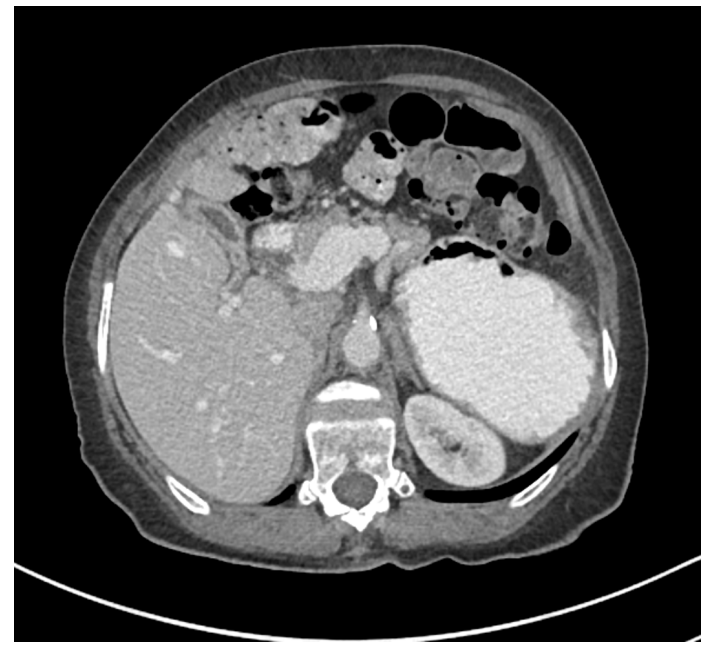

Figure 2 Preoperative axial CT demonstrating the absence of the spleen in the left upper quadrant.

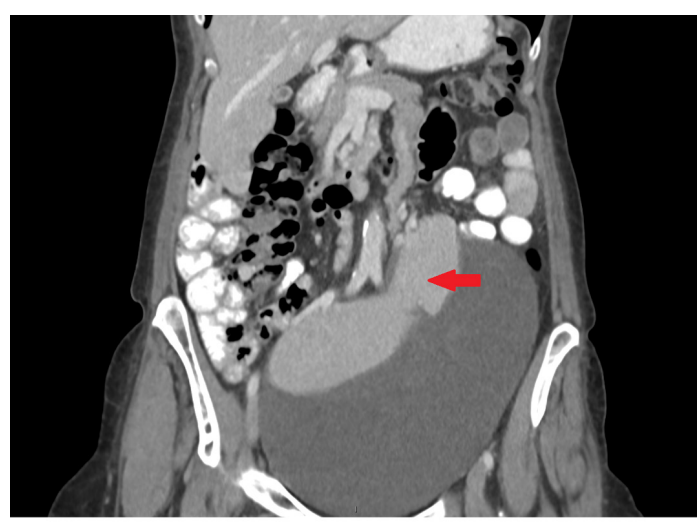

Figure 3 Coronal reconstruction of the preoperative CT scan (figure 2) showing the spleen in the pelvis (arrow) with a large subcapsular haematoma.

$38.5 \%$, platelets $469 \mathrm{k} / \mathrm{uL}$ ). Her final pathology revealed a $17 \times 12 \times 5 \mathrm{~cm}$ spleen with congestion and without evidence of lymphoma. The only identifiable aetiology for the subcapsular splenic haemorrhage was the episode of severe emesis 2 months prior to presentation in the setting of relative thrombocytopaenia.

A wandering spleen comprises less than $0.2 \%$ of all splenectomies and is characterised by migration of the spleen from the left upper quadrant to elsewhere in the abdomen. ${ }^{1}$ Most patients present in childhood, resulting from a congenital anomaly in the mesogastrium or splenic suspensory ligaments or in adulthood when women develop an acquired laxity of those ligaments after hormonal changes in pregnancy. ${ }^{12}$ The most common presentation is an asymptomatic abdominal mass or abdominal pain caused by torsion of the spleen on its pedicle. ${ }^{2}$ Several medical conditions present in our case, including a 


\section{Learning points}

Splenic subcapsular haematomas, previous pregnancies, splenomegaly and lymphoma are risk factors for a wandering spleen.

- CT scan is the preferred diagnostic study and a delay in diagnosis can result in torsion of the splenic vascular pedicle and splenic necrosis, leading to an acute abdomen.

- Both splenectomy and splenopexy are surgical options, but splenopexy preserves the immunological function of the spleen.

history of splenomegaly, lymphoma and prior pregnancy, are known risk factors for spleen migration. ${ }^{3}$ Thus, a wandering spleen should be on the differential diagnosis for any new abdominal mass in patients with any of these factors, especially in cases with thrombocytopaenia posing additional risk of subcapsular haemorrhage. Patients who experience torsion of the splenic vascular pedicle or spleen necrosis may present with an acute abdomen ${ }^{1}$ and CT scans are the preferred diagnostic study. ${ }^{1}$ Splenectomy has been the treatment of choice but splenopexy has been successfully reported in patients with viable spleens..$^{13}$ Our patient underwent a splenectomy due to the large subcapsular haematoma, after which her thrombocytopaenia resolved.

Acknowledgements We would like to thank Dr Andrew Dwyer (deceased) for his astute radiographic diagnosis of this wandering spleen.

Contributors CMK and PS cared for the patient during the acute episode described in the case and prepared the manuscript. DHF was the primary investigator for the patient's haematopoietic cell transplant that resulted in the acute episode and has reviewed and edited the manuscript.

Funding The authors have not declared a specific grant for this research from any funding agency in the public, commercial or not-for-profit sectors.

Competing interests None declared.

Patient consent Obtained.

Provenance and peer review Not commissioned; externally peer reviewed.

\section{REFERENCES}

1 Mehta A, Vana PG, Glynn L. Splenic torsion after congenital diaphragmatic hernia repair: case report and review of the literature. J Pediatr Surg 2013;48:e29-31.

2 Brown CV, Virgilio GR, Vazquez WD. Wandering spleen and its complications in children: a case series and review of the literature. J Pediatr Surg 2003;38:1676-9.

3 Soleimani M, Mehrabi A, Kashfi A, et al. Surgical treatment of patients with wandering spleen: report of six cases with a review of the literature. Surg Today 2007;37:261-9.

Copyright 2018 BMJ Publishing Group. All rights reserved. For permission to reuse any of this content visit

http://group.bmj.com/group/rights-licensing/permissions.

BMJ Case Report Fellows may re-use this article for personal use and teaching without any further permission.

Become a Fellow of BMJ Case Reports today and you can:

- Submit as many cases as you like

- Enjoy fast sympathetic peer review and rapid publication of accepted articles

- Access all the published articles

- Re-use any of the published material for personal use and teaching without further permission

For information on Institutional Fellowships contact consortiasales@bmjgroup.com

Visit casereports.bmj.com for more articles like this and to become a Fellow 